\title{
ORIGINAL
}

\section{VIGILANCIA DE LA PANDEMIA DE GRIPE (H1N1) 2009 EN ESPAÑA}

\author{
Amparo Larrauri Cámara, Silvia Jiménez-Jorge, Lorena Simón Méndez, Salvador de Mateo \\ Ontañón, en representación del Sistema de Vigilancia de Gripe en España (SVGE)*. \\ Área de Vigilancia de la Salud Pública. Centro Nacional de Epidemiología. Instituto de Salud Carlos III. Madrid.
}

\section{RESUMEN}

Fundamento: España experimentó una circulación del nuevo virus de la gripe (H1N1)2009 durante el verano de 2009, que evolucionó de forma creciente hasta la presentación a principios del otoño de la primera onda pandémica por dicho virus. Los objetivos de este trabajo son describir la evolución de esta onda pandémica en nuestro país y evaluar su impacto en la morbilidad y mortalidad de la población española.

Método: A partir de la información proporcionada por el Sistema de Vigilancia de la Gripe en España y el Centro de Coordinación de Alertas y Emergencias del Ministerio de Sanidad y Política Social se han estimado una serie de indicadores epidemiológicos y virológicos para evaluar el nivel de actividad e intensidad de la onda pandémica, así como su gravedad.

Resultados: La onda pandémica por el virus (H1N1)2009 se inició a comienzos del otoño de 2009 y registró valores máximos de incidencia de gripe de 372,15 casos semanales/100.000 habitantes. Las mayores tasas de incidencia de gripe se observaron en los menores de 15 años. La tasa de detección viral en el periodo pandémico se mantuvo en el rango de las registradas previamente $(46,4 \%)$. Se estimó una tasa de letalidad global de 0,43 defunciones por 1.000 casos de gripe pandémica. Un $64 \%$ de las defunciones por gripe pandémica se registraron en adultos jóvenes, con máximas tasas de mortalidad en el grupo de 45-64 años (9,35 defunciones/1.000.000 habitantes). La mortalidad asociada a gripe estacional en el periodo 20012008 fue máxima en los mayores de 64 años (95\% del total de defunciones).

Conclusiones: La onda pandémica por el virus de la gripe (H1N1)2009 tuvo una presentación precoz en España y una intensidad media en comparación con las trece ondas estacionales previas de gripe. Esta primera onda también se caracterizó por un carácter leve, teniendo en cuenta tasas de letalidad o mortalidad, si bien un elevado porcentaje de las defunciones confirmadas por el nuevo virus se ha observado en menores de 65 años.

Palabras clave: Gripe humana. Vigilancia sanitaria. Virus de la Influenza A H1N1 de origen Porcino. Morbilidad. Mortalidad.

Correspondencia:

Amparo Larrauri Cámara

Centro Nacional de Epidemiología, Instituto de Salud Carlos III

Monforte de Lemos, 5

28029 Madrid

alarrauri@isciii.es

\section{ABSTRACT \\ Surveillance of influenza Pandemic (H1N1)2009 in Spain}

Background: During the summer of 2009, Spain experienced the circulation of the novel influenza (H1N1)2009 virus, beyond the usual period of influenza activity, increasingly evolving up to the presentation in the early autumn of the first wave of the pandemic virus. The objectives of this study are to describe the evolution of the pandemic wave in our country and to assess their impact on morbidity and mortality of the Spanish population.

Method: From the information obtained from the Spanish Influenza Surveillance System and the Coordinating Centre for Health Alerts and Emergencies within Spanish Ministry of Health and Social Policy have been estimated a number of epidemiological and virological indicators that were used to assess the level of activity and intensity of the pandemic wave, as well as its severity

Results: The beginning of the pandemic wave in Spain started in early autumn 2009 reaching the maximum weekly incidence rate of 372.15 cases $/ 100,000$ inhabitants. The highest incidence was registered in under 15 years old. Viral detection rate registered during the pandemic period remained at the range of previously recorded $(46.4 \%)$. We estimated an overall mortality rate of 0.43 deaths per 1,000 pandemic cases. The $64 \%$ of deaths from pandemic influenza occurred in young adults and the highest mortality rates were registered in the 45-64 years age group with 9.35 deaths/1,000,000 inhabitants. Mortality associated with seasonal influenza in the period 2001-2008 was highest in those over 64 years ( $95 \%$ of all deaths).

Conclusions: The influenza (H1N1)2009 pandemic wave in Spain showed an early presentation and a medium level of influenza intensity compared to the previous thirteen seasonal influenza waves. Considering lethality or mortality rates, this first pandemic wave was also characterized by a mild severity, although a high percentage of deaths confirmed by the new virus were observed in population under 65 years.

Key words: Influenza. Human. Sentinel Surveillance. SwineOrigin Influenza A H1N1 Virus. Morbidity. Mortality.

Conflicto de intereses:

No hay conflicto de intereses. 


\section{INTRODUCCIÓN}

La aparición de casos de infección humana por un nuevo virus de la gripe (H1N1) 2009 en abril de 2009, en Méjico y EE UU', junto a la comprobación de una transmisión interhumana del virus, llevó a la Organización Mundial de la Salud (OMS) a elevar a fase 5 el nivel de alerta pandémico el 29 de abril y a fase 6 el 11 de junio, como respuesta a una transmisión sostenida del mismo virus en dos de las regiones mundiales ${ }^{2}$. España, como la mayoría de países del hemisferio Norte $^{3}$, experimentó una circulación de virus (H1N1)2009 durante el verano de 2009, fuera del periodo habitual de actividad gripal, que evolucionó de forma creciente hasta la presentación a principios del otoño de 2009 de la primera onda pandémica en nuestro territorio. La estrategia de vigilancia de casos humanos de infección por el virus pandémico se fue adaptando en nuestro país a la evolución de la pandemia ${ }^{4}$, de acuerdo con el Plan Nacional de Preparación y Respuesta frente a una pandemia de gripe y las recomendaciones internacionales ${ }^{5,6}$.

Tras la declaración de fase 5 de alerta pandémica, el Centro Europeo para el Control de Enfermedades (ECDC) y la OMS recomendaron prolongar la vigilancia de la gripe estacional mediante los sistemas de vigilancia de gripe habituales, intensificando las medidas de contención. Posteriormente, en junio de 2009, tras declarar la OMS la fase 6 de alerta pandémica, se recomendó la adopción de una estrategia de vigilancia acorde con una fase de mitigación, en la que la vigilancia del virus pandémico a través de los sistemas rutinarios de vigilancia de gripe sustituyera paulatinamente a la notificación individualizada de casos confirmados por laboratorio $^{6,7}$. El cambio de estrategias de vigilancia se produjo paulatinamente en el Estado español a lo largo del mes de junio y julio de 2009 y fue ratificado por el Consejo Interterritorial del Sistema Nacional de Salud el 22 de julio de $2009^{7}$. De esta forma, a partir de la semana 29/2009 (del 19 al 25 de julio), la evolución de la pandemia se monitorizó mediante la información epidemiológica y virológica proporcionada por el Sistema de Vigilancia de la Gripe en España (SVGE).

Siguiendo las citadas recomendaciones, la actividad de vigilancia de gripe a través del SVGE se mantuvo íntegramente a partir de la semana 19/2009 (del 10 al 16 de mayo). En periodos interpandémicos este sistema de vigilancia centinela (integrado desde 1996 en la red de vigilancia europea de gripe -EISN-, coordinada actualmente por el $\mathrm{ECDC}^{8}$ ) suele interrumpirse en el periodo de menor actividad gripal, pero ante la situación creada se acordó su mantenimiento y refuerzo para ayudar a una vigilancia eficaz de la pandemia. Durante el verano de 2009 este refuerzo se tradujo en dos aspectos fundamentales: el aumento de los médicos centinela participantes y un incremento del número de muestras recogidas de los pacientes para confirmación virológica de la enfermedad.

El objetivo de este trabajo es describir la evolución de la pandemia por virus (H1N1)2009 en España durante el verano de 2009 y en la posterior onda pandémica y evaluar su impacto en la morbilidad y mortalidad de la población española, comparándolo con el de las temporadas de gripe estacional previas.

\section{MATERIAL Y MÉTODOS}

El Sistema de Vigilancia de la Gripe en España (SVGE) es un sistema de vigilancia de la gripe de ámbito estatal, coordinado por el Centro Nacional de Epidemiología (CNE, ISCIII) y el Centro Nacional de Referencia de Gripe (Centro Nacional de Gripe de la OMS del Centro Nacional de Microbiología -CNM-, ISCIII, Majadahonda, Madrid) y formado por una serie de redes autonómicas de médicos generales y pediatras (MP) centinela voluntarios, así como por un conjunto 
de laboratorios de microbiología con capacidad de detección de virus de la gripe. A comienzos de la temporada 2008-2009 participaban en el sistema 524 médicos de atención primaria y 173 pediatras, con una población vigilada de 926.092 habitantes, aproximadamente un 2,1\% de la población, correspondiente a las $16 \mathrm{CCAA}$ con redes centinela de vigilancia de gripe (todas a excepción de Melilla, y Galicia y Murcia que colaboran con la vigilancia virológica). En la temporada 2009-2010 la red centinela de Melilla se incorporó al SVGE, siendo 17 las CCAA con redes centinela de vigilancia de gripe, con una población vigilada total de 1.131.012 habitantes. Cumpliendo con las recomendaciones de mantener y reforzar el SVGE a partir de la semana 20/2009 (del 17 al 23 de mayo), el sistema aumentó el número de MP centinela participantes $(22 \%$ de incremento), con el resultado de una mayor cobertura de población vigilada $(2,53 \%$ de la población total).

Los MP centinela notifican semanalmente los casos de gripe detectados en sus poblaciones de referencia siguiendo una definición de caso. Hasta esa temporada (20082009), las redes de vigilancia centinela de gripe habían utilizado la definición de caso de gripe de la CIPSAP (Clasificación Internacional de Problemas de Salud en Atención primaria ${ }^{9}$ ), cambiando en la temporada 2009-2010 a la propuesta por la Unión Europea (UE) que comprende la aparición súbita de los síntomas y al menos uno de los siguientes cuatro síntomas generales: fiebre o febrícula, malestar general, cefalea, mialgia y al menos uno de los siguientes tres síntomas respiratorios: tos, dolor de garganta, disnea, junto a la ausencia de otra sospecha diagnóstica ${ }^{10}$.

Para la vigilancia virológica los MP centinela toman frotis nasal o nasofaríngeo de los pacientes con gripe y los envían a los laboratorios del SVGE para la detección de virus gripales y tipado/subtipado de los mismos. En un principio y para favorecer la especifi- cidad del SVGE se confirmaron todos los casos de gripe que cumplían la definición. La estrategia de toma de muestras fue cambiando a lo largo del verano de 2009, conforme se intensificaba la circulación del virus pandémico y en función de las capacidades de los laboratorios de microbiología, pasando de una confirmación de todos los casos de gripe a un muestreo sistemático de los pacientes que consultaban a los MP centinela. Además de las muestras respiratorias procedentes de las consultas centinela, se notificaron al SVGE, como en temporadas de gripe previas, detecciones gripales procedentes de otras fuentes «no centinela» (ej.: hospitales, laboratorios colaboradores, etcétera.).

La detección del virus (H1N1)2009 se realizó mediante una PCR anidada múltiple de transcriptasa inversa para subtipar el gen de la hemaglutinina de los virus de la gripe A. La identificación de los virus (H1N1) 2009 se llevó a cabo mediante el análisis secuencial del producto de amplificación de este ensayo.

La información recogida por el SVGE incluye habitualmente datos demográficos, datos clínicos y de laboratorio y estado de vacunación de los casos diagnosticados de gripe, añadiéndose en esta última temporada la recogida más detallada de síntomas y signos clínicos, así como presencia de patologías crónicas subyacentes y embarazo. Los datos semanales de vigilancia de gripe se siguieron insertando por cada red centinela en una aplicación informática vía Web y se analizaron a nivel central en el Centro Nacional de Epidemiología, para proporcionar una información puntual sobre la evolución de la pandemia en España a nivel autonómico y nacional (http://vgripe.isciii.es/ gripe).

A partir de la información proporcionada por el SVGE, desde la temporada 1996-1997 hasta la 2009-2010, se han estimado: 1) Indicadores epidemiológicos: Tasas de incidencia semanal de gripe y tasas de incidencia 
acumulada de gripe por temporada y grupo de edad; porcentaje de casos de gripe pandémica clínica con respecto a la población española por grupo de edad, porcentaje de toma de muestras por temporada, periodo y grupo de edad. Para el cálculo de incidencias semanales y acumuladas de gripe se ha utilizado como denominador la población vigilada en cada red centinela; 2) Indicadores virológicos: Porcentaje de muestras positivas por temporada (tasa de detección viral) y semanas; distribución de virus gripales por tipo/subtipo por periodo y grupo de edad. Se ha considerado periodo epidémico de cada temporada de gripe al correspondiente a las semanas epidemiológicas en las que la incidencia de gripe sobrepasa el umbral basal de actividad y el porcentaje de muestras positivas es mayor del $30 \%$. Por otra parte, el umbral basal de actividad gripal semanal se ha establecido para cada temporada como una media de la incidencia de las cinco temporadas anteriores, excluidas las temporadas con incidencias excepcionalmente bajas, y se ha verificado con la aplicación de un método de ondas epidémicas móviles ${ }^{11}$. Para la comparación de incidencias en distintas zonas geográficas o periodos de tiempo se ha calculado la razón de tasas de forma puntual y de intervalo (IC 95\%), previo ajuste de las tasas por edad.

Con los casos de gripe notificados al SVGE se ha estimado el número de casos confirmados de gripe pandémica, desde la semana 20/2009 a la 19/2010, a partir de las incidencias semanales de gripe, corregidas por la tasa de detección de virus (H1N1)2009. Las defunciones por virus pandémico desde abril de 2009 hasta marzo de 2010 se obtuvieron del registro de casos graves y defunciones del Centro de Coordinación de Alertas y Emergencias del Ministerio de Sanidad y Política Social, y las debidas a gripe estacional (CIE-10: J09-J11), durante el periodo 2000-2008, se obtuvieron del registro de mortalidad del Instituto Nacional de Estadística (INE). La letalidad por virus pandémico en la última temporada se ha calculado utilizando el número de casos estimados de gripe pandémica hasta marzo de 2010 como denominador, mientras que para las tasas de mortalidad tanto de gripe estacional como pandémica se han usado las proyecciones de población del INE. En ambos casos se obtuvieron estimaciones puntuales de las tasas y estimaciones de intervalo, asumiendo una distribución de Poisson.

\section{RESULTADOS}

El refuerzo del SVGE con motivo de la pandemia se tradujo en un incremento del número de muestras recogidas para confirmación virológica de la enfermedad. La proporción de pacientes a los que se tomó muestra respiratoria, con respecto al total de casos de gripe notificados en los períodos señalados, llegó a ser en el verano de 2009 (semanas 20/2009 - 39/2009) de un 70\% y durante todo el periodo pandémico del $38 \%$, frente al $16 \%$ de temporadas anteriores. Este aumento se constató tanto a nivel global, como en todos los grupos de edad analizados (tabla 1).

La circulación autóctona del virus pandémico (H1N1)2009 se detectó en la semana 21/2009 (del 24 al 30 de mayo) y circuló simultáneamente con los virus de la gripe estacional AH3N2 y B. A mediados de julio el virus pandémico (H1N1)2009 se había difundido y era predominante en toda España. Sólo a partir de enero de 2010, tras la onda pandémica de 2009, se observó de nuevo una co-circulación con virus de la gripe estacional de tipo B.

El nivel de actividad gripal en España permaneció por encima de los valores propios del periodo estival y se notificaron brotes localizados por virus (H1N1)2009 durante todo el verano, especialmente asociados a instituciones juveniles. En la figura 1 se muestra la evolución de la tasa de incidencia de gripe semanal durante el periodo habitual 
Tabla 1

Proporción de toma de muestras para confirmación virológica. Sistemas centinela. Periodo 2002-2009 y periodo pandémico. España

\begin{tabular}{|c|c|c|}
\hline \multirow{2}{*}{ Grupos de edad (años) } & \multicolumn{2}{|c|}{ Proporción de toma de muestras (\%) } \\
\cline { 2 - 3 } & $\mathbf{2 0 0 2 - 2 0 0 9 *}^{*}$ & Periodo pandémico** $^{*}$ \\
\hline $0-4$ & 25,3 & 41,2 \\
\hline $5-14$ & 17,3 & 31,3 \\
\hline $15-44$ & 14,2 & 41,9 \\
\hline $45-64$ & 12,6 & 39,6 \\
\hline$>64$ & 11,8 & 40,5 \\
\hline Total & 15,6 & 37,8 \\
\hline
\end{tabular}

* Periodo 2002-2009: Temporadas 2002-2003 hasta la 2008-2009.

** Periodo pandémico: Desde la semana 20/2009 hasta la 20/2010.

de vigilancia de la temporada 2008-2009 y durante el periodo pandémico en España, con tasas máximas de incidencia de gripe de 211 y 372 casos/100.000 habitantes, respectivamente. La tasa global de incidencia de gripe aumentó progresivamente durante el verano de 2009, aunque no se superó el umbral basal hasta la semana 38/2009 (del 20 al 26 de septiembre). Se considera que el inicio de la onda pandémica por (H1N1) 2009 en España se produjo en la semana 40/2009 (del 4 al 10 de octubre) en la que, además de valores de incidencia de gripe por encima del umbral basal (63 casos/100.000 habitantes), la tasa de detección viral (45\%) alcanzó la mediana de este indicador en los comienzos de las ocho ondas estacionales de gripe previas (figura 2). Esta fecha de inicio de la onda pandémica podemos calificarla de precoz si la comparamos con la de las ondas epidémicas de temporadas anteriores (tabla 2). Los inicios de las ondas epidémicas suelen producirse en nuestro país a finales del mes de diciembre o principios del mes de enero ( $70 \%$ de las temporadas analizadas), si bien antecedentes de periodos epidémicos tempranos se dieron en las temporadas
1996-1997 y 2003-2004, con inicios de ondas estacionales de gripe entre octubre y noviembre.

El pico máximo de incidencia de gripe se alcanzó en la semana 46/2009 (del 15 al 21 de noviembre) con 372,15 casos por 100.000 habitantes (figura 2), volviéndose a registrar valores pre-epidémicos a partir de la semana 50/2009 (del 13 al 19 de diciembre). Tanto la duración de la onda pandémica (11 semanas), como el nivel de intensidad gripal evaluada por esa tasa máxima de incidencia, se sitúan en el rango de los observados en las últimas 13 temporadas gripales (tabla $2 \mathrm{y}$ figura 3). Las mayores tasas de incidencia de gripe a lo largo del periodo pandémico se registraron en los menores de 15 años (figura 4), con un valor máximo de incidencia semanal de 1.104 casos por 100.000 habitantes, en el pico de la pandemia, para el grupo de 5-14 años.

Las tasas de incidencia acumulada en la temporada 2009-2010 fueron de 7.550 y 5.240 casos de gripe clínica por 100.000 habitantes en los grupos de 5-14 años y 


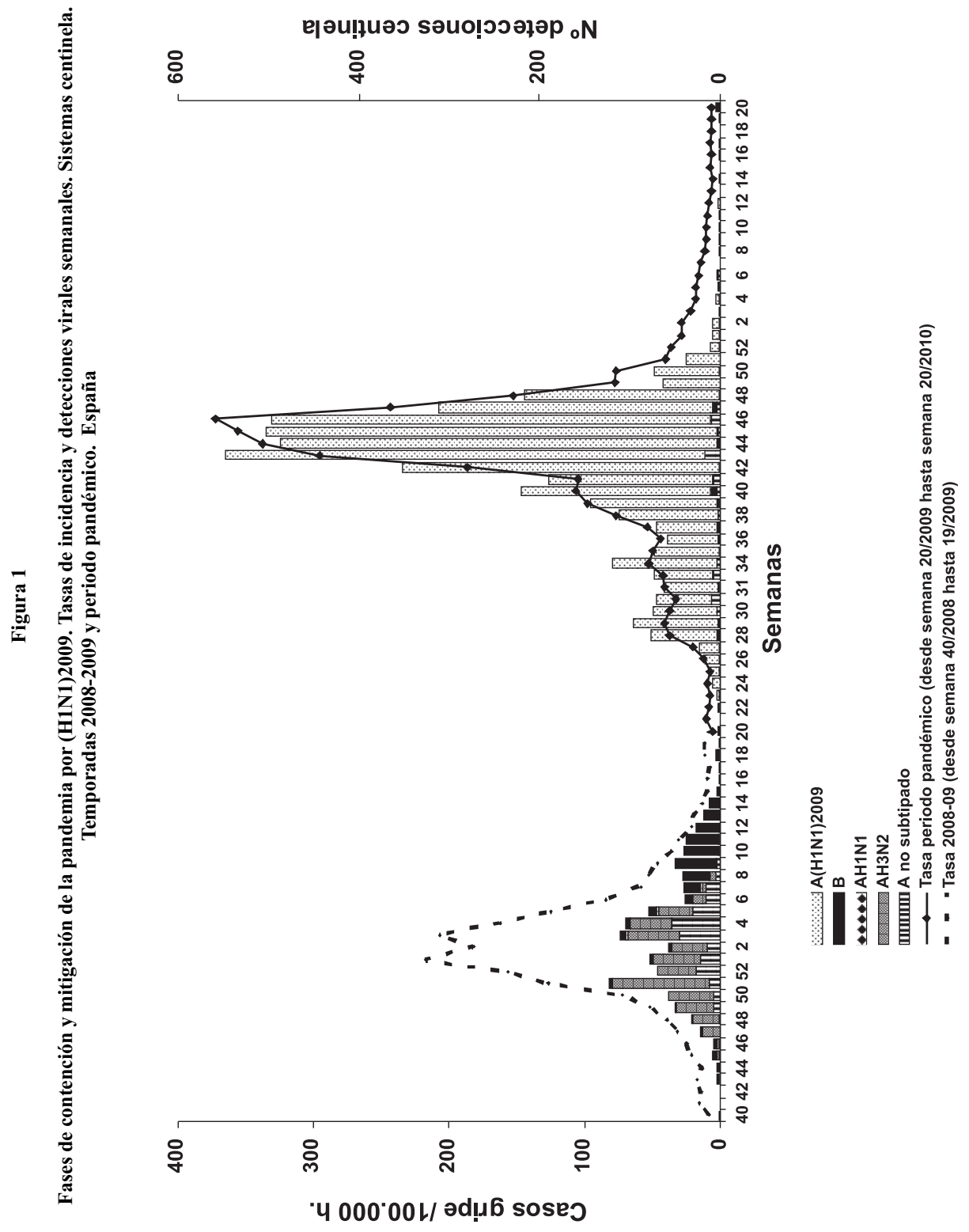




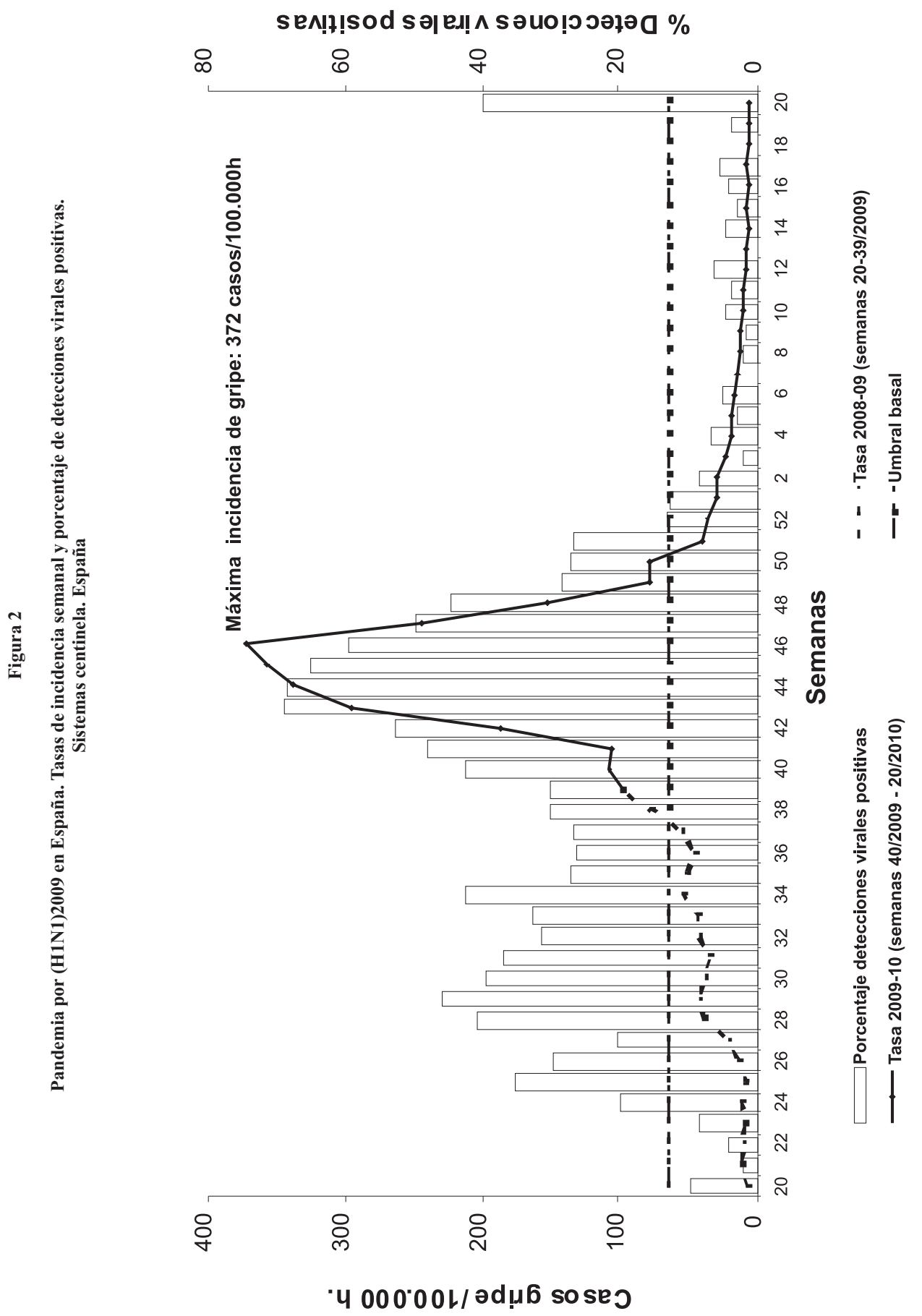


Tabla 2

Periodos epidémicos de gripe y tipo/subtipo de virus dominante. Temporadas 1996-1997 a 2009-2010. España

\begin{tabular}{|c|c|c|c|c|c|c|}
\hline & \multicolumn{5}{|c|}{ Período epidémico } \\
\cline { 2 - 7 } Temporadas & $\begin{array}{c}\text { Semana } \\
\text { Inicio }\end{array}$ & $\begin{array}{c}\text { Semana } \\
\text { Pico }\end{array}$ & $\begin{array}{c}\text { Semana } \\
\text { Fin }\end{array}$ & $\begin{array}{c}\text { Muración } \\
\text { (semanas) }\end{array}$ & $\begin{array}{c}\text { Máxima } \\
\text { incidencia } \\
\text { (casos/100.000 } \\
\text { habitantes) }\end{array}$ & $\begin{array}{c}\text { Tipo/subtipo } \\
\text { dominante }\end{array}$ \\
\hline $1996-1997$ & $45 / 1996$ & $50 / 1996$ & $09 / 1997$ & 17 & 259,09 & AH3N2/B \\
$1997-1998$ & $51 / 1997$ & $04 / 1998$ & $09 / 1998$ & 11 & 306,88 & AH3N2/B \\
$1998-1999$ & $52 / 1998$ & $03 / 1999$ & $10 / 1999$ & 11 & 434,26 & B/AH3N2 \\
$1999-2000$ & $51 / 1999$ & $02 / 2000$ & $06 / 2000$ & 8 & 452,27 & AH1N1 \\
$2000-2001 *$ & - & - & - & - & - & AH1N1/B \\
$2001-2002$ & $01 / 2002$ & $04 / 2002$ & $10 / 2002$ & 10 & 397,19 & AH3N2/B \\
$2002-2003$ & $50 / 2002$ & $04 / 2003$ & $11 / 2003$ & 14 & 139,54 & B/AH1N1 \\
$2003-2004$ & $43 / 2003$ & $47 / 2003$ & $52 / 2003$ & 10 & 225,02 & AH3N2 \\
$2004-2005$ & $50 / 2004$ & $02 / 2005$ & $10 / 2005$ & 13 & 542,86 & AH3N2/B \\
$2005-2006$ & $08 / 2006$ & $11 / 2006$ & $14 / 2006$ & 7 & 166,07 & AH1N1/B \\
$2006-2007$ & $02 / 2007$ & $06 / 2007$ & $09 / 2007$ & 8 & 259,69 & AH3N2/B \\
$2007-2008$ & $50 / 2007$ & $02 / 2008$ & $09 / 2008$ & 12 & 202,76 & AH1N1/B \\
$2008-2009$ & $50 / 2008$ & $53 / 2008$ & $07 / 2009$ & 11 & 218,31 & AH3N2/B \\
$2009-2010$ & $40 / 2009$ & $46 / 2009$ & $50 / 2009$ & 11 & 372,72 & (H1N1)2009 \\
\hline
\end{tabular}

* No se superó el umbral basal en toda la temporada por lo que no se ha establecido periodo epidémico.

menores de 5 años, respectivamente. En la figura 5 se representa una comparación entre las tasas acumuladas de gripe por grupo de edad en el periodo comprendido entre las temporadas 1997-1998 a 2008-2009 y la temporada 2009-2010. La razón de tasas de incidencia acumulada de gripe en la temporada 2009-2010 y la mediana del periodo 1997-2009 fue de 2,01 (IC 95\%: 1,96-2,06) y 1,65 (IC 95\%: 1,58-1,71), para los grupos de 5-14 años y 0-4 años, respectivamente. En los mayores de 64 años se registraron tasas acumuladas de gripe significativamente menores que en las temporadas estacionales previas, con una razón de 0,48 (IC 95\%: $0,45-0,53)$. Se estima que las tasas de ataque de gripe clínica durante el periodo pandémico fueron de $6,7 \%, 9,5 \%, 2,8 \%$ y $0,6 \%$ para los grupos de 0-4, 5-14, 15-64 y más de 64 años, respectivamente. En contraste, la mediana de las tasas de ataque de gripe clínica en las 13 temporadas estacionales de gripe previas, ofrece valores de $3,0 \%, 3,7 \%$, $2,1 \%$ y $0,7 \%$ para los mismos grupos de edad.

Las características clínicas de los casos centinela confirmados de gripe (H1N1)2009 notificados al SVGE revelaron un cuadro leve similar al de la gripe estacional, señalándose como síntomas más frecuentes la fiebre (97\%) y tos (92\%). Así mismo, el 87\% de los casos confirmados de gripe pandémica que acudieron a la consulta centinela no presentaron ningún factor de riesgo de complicaciones por gripe. En el resto de pacientes con gripe pandémica los factores de riesgo más señalados fueron enfermedad respiratoria crónica $(9,3 \%)$ y otras enfermedades $(2,7 \%)$. 


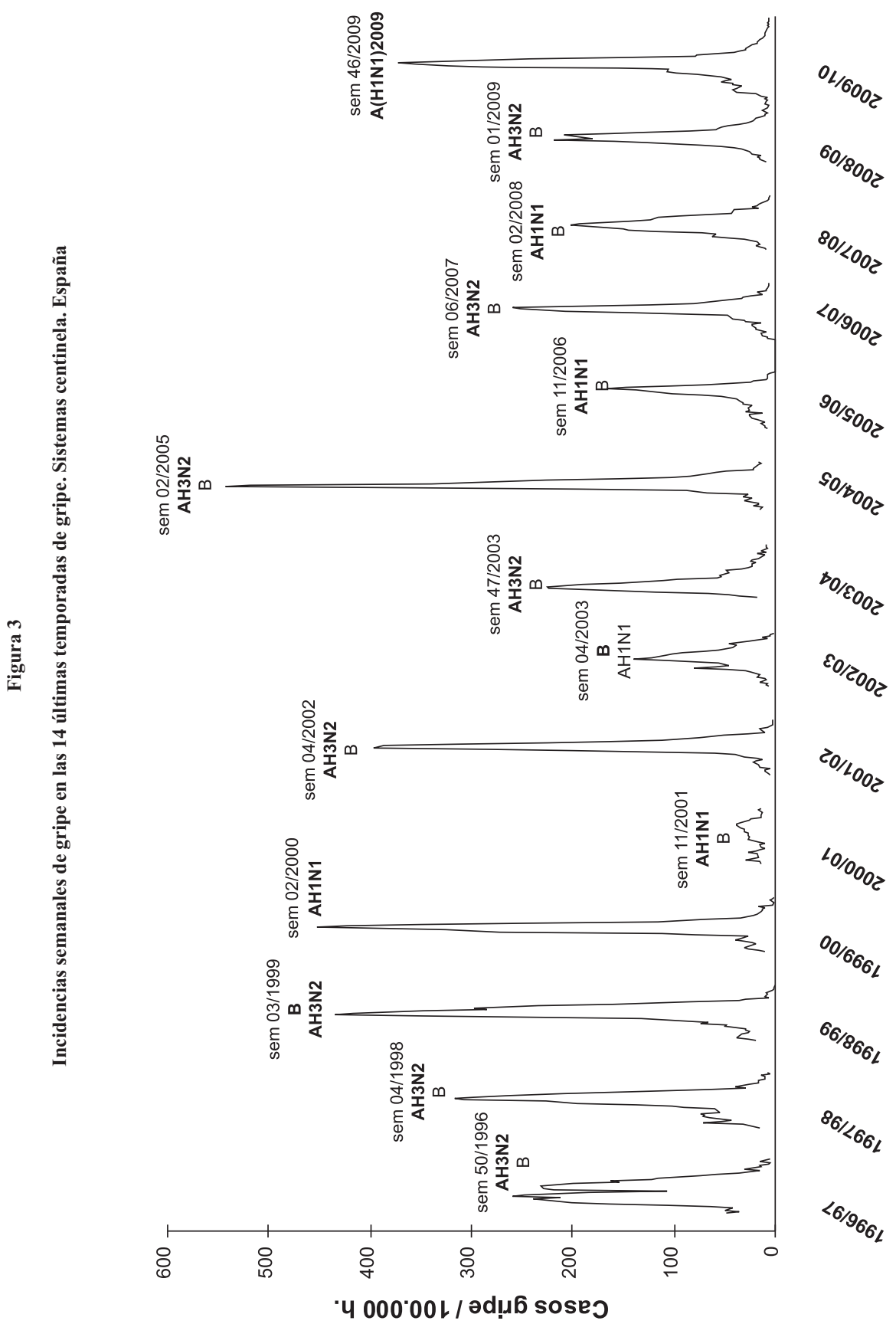




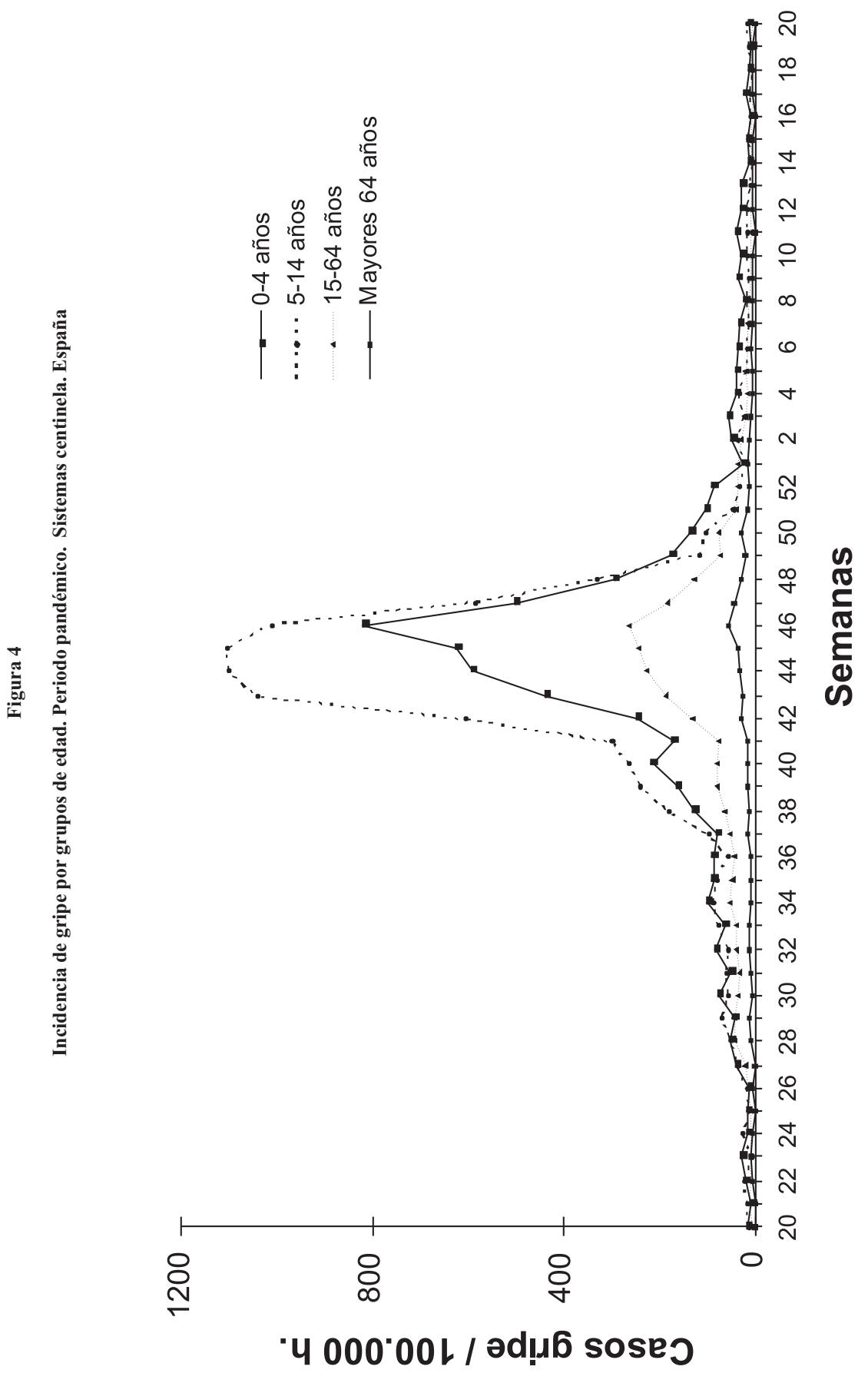


Figura 5

Tasas acumuladas de gripe por grupos de edad. Temporadas 1997-1998 a 2008-2009 versus temporada 2009-2010.

Sistemas centinela. España

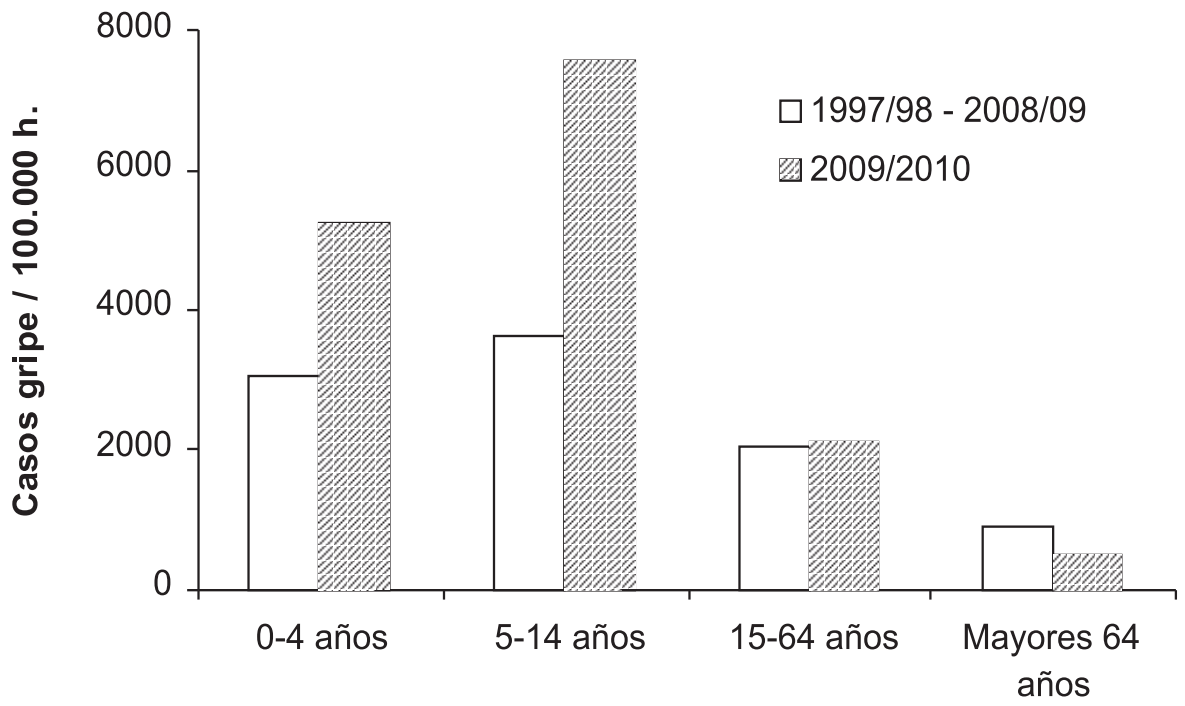

Grupos de edad

En el periodo pandémico se analizaron muestras respiratorias de 10.955 pacientes centinela, de las que 7.696 se recogieron después del verano 2009, durante la onda pandémica de la temporada 2009-2010 (tabla 3). La tasa de detección viral, indicador de la intensidad de la circulación viral, se situó en valores superiores al 25-30\% desde la semana $24 / 2009$ (del 14 al 20 de junio) (figura 2) y aumentó de un 30\% en el verano de 2009 al $46 \%$ en la temporada 2009-2010, en consonancia con un aumento en el número de detecciones centinela del virus (H1N1) 2009. De los 4557 casos de gripe centinela confirmados en el periodo pandémico, 4375 (96\%) correspondieron al nuevo virus (H1N1) 2009 (tabla 3).

Una distribución del número de muestras centinela recogidas y la tasa de detección viral desde la temporada 2001-2002 hasta la 2009-2010 se muestra en la tabla 4. El número de pacientes a los que se les tomó muestra respiratoria en la temporada de gripe pandémica fue de tres a seis veces superior al registrado en las temporadas de gripe estacional previas, si bien la tasa de detección viral se mantuvo en el rango de las registradas previamente (tabla 4).

Durante el periodo pandémico los laboratorios del SVGE notificaron la detección de 10.761 virus gripales, $44 \%$ procedentes de fuentes centinela y $56 \%$ de no centinela. El $98 \%$ del total de detecciones virales fueron virus de la gripe A (99,5\% de (H1N1) 2009 entre los subtipados), $1,4 \%$ virus de la gripe $\mathrm{B}$ y $0,1 \%$ virus de la gripe $\mathrm{C}$. En la temporada 2009-2010 se subtiparon el 98\% del total de virus notificados, frente al $61 \%$ y $70 \%$ 
Tabla 3

Tasa de detección viral y proporción de virus (H1N1)2009. Sistemas centinela. Verano 2009, temporada 2009-2010 y periodo pandémico. España

\begin{tabular}{|l|c|c|c|}
\hline \multicolumn{1}{|c|}{ Periodos } & $\begin{array}{c}\mathbf{N}^{\mathbf{0}} \text { muestras } \\
\text { centinela (N) }\end{array}$ & $\begin{array}{c}\text { Tasa detección } \\
\text { viral (\%) }\end{array}$ & $\begin{array}{c}\text { Virus } \\
\text { (H1N1)2009 } \\
\mathbf{N}(\% \text { del total de } \\
\text { detecciones gripales) }\end{array}$ \\
\hline Verano 2009* & 3.259 & 30,1 & $905(93 \%)$ \\
\hline Temporada 2009-2010 & 7.696 & 46,4 & $3.470(97 \%)$ \\
\hline Periodo pandémico** & 10.955 & 41,6 & $4.375(96 \%)$ \\
\hline
\end{tabular}

* Verano 2009: Desde la semana 20/2009 hasta la semana 39/2009.

** Periodo pandémico: Desde la semana 20/2009 hasta la 20/2010.

Tabla 4

Muestras respiratorias positivas y tasa de detección viral. Sistemas centinela. Temporadas 2001-2002 a 2009-2010. España

\begin{tabular}{|c|c|c|}
\hline Temporadas & $\begin{array}{c}\mathbf{N}^{\mathbf{0}} \text { muestras } \\
\text { centinela (N) }\end{array}$ & $\begin{array}{c}\text { Tasa detección } \\
\text { viral (\%) }\end{array}$ \\
\hline $2001-2002$ & 1.214 & 43,4 \\
\hline $2002-2003$ & 1.437 & 30,5 \\
\hline $2003-2004$ & 1.389 & 31,3 \\
\hline $2004-2005$ & 1.789 & 46,0 \\
\hline $2005-2006$ & 1.885 & 31,0 \\
\hline $2006-2007$ & 1.855 & 45,0 \\
\hline $2007-2008$ & 2.019 & 49,0 \\
\hline $2008-2009$ & 2.557 & 44,0 \\
\hline $2009-2010$ & 7.696 & 46,4 \\
\hline
\end{tabular}

registrado en las dos últimas temporadas. En la tabla 5 se muestra la distribución de las detecciones de virus de la gripe, centinela y no centinela, por tipo/subtipo, desde la temporada 1996-1997 hasta la 2009-2010, así como el porcentaje con respecto al total de detecciones virales de la temporada, obser- vándose un patrón de circulación mixta de virus de la gripe en todas las temporadas estacionales de gripe, con excepción de las temporadas 2003-2004 y la 2009-2010 en las que circuló de forma prácticamente absoluta el virus $\mathrm{AH} 3 \mathrm{~N} 2$ y el virus pandémico, respectivamente. 
Tabla 5

Detecciones por tipo/subtipo de virus gripales (muestras centinela y no centinela).

Temporadas 1997-1998 a 2009-2010. Grupo de Vigilancia de la gripe en España

\begin{tabular}{|c|c|c|c|c|c|c|c|}
\hline \multirow[b]{2}{*}{ Temporadas } & \multicolumn{5}{|c|}{ Virus de la gripe $A$} & \multirow[b]{2}{*}{$\begin{array}{c}\text { Virus de la } \\
\text { gripe B } \\
\text {-n (\%)- }\end{array}$} & \multirow[b]{2}{*}{ Total (n) } \\
\hline & $\begin{array}{c}\text { Total A -n } \\
\text { (\%)- }\end{array}$ & ANS (\%) & AH3N2 (\%) & AH1N1 (\%) & $\begin{array}{c}\text { (H1N1) } \\
2009(\%)\end{array}$ & & \\
\hline $1997-1998$ & $156(98,1 \%)$ & 88,5 & 11,5 & 0,0 & & $3(1,9 \%)$ & 159 \\
\hline 1998-1999 & $123(36,5 \%)$ & 97,0 & 3,0 & 0,0 & & $214(63,5 \%)$ & 337 \\
\hline $1999-2000$ & $476(99,8 \%)$ & 64,5 & 12,4 & 23,1 & & $1(0,2 \%)$ & 477 \\
\hline $2000-2001$ & $101(71,6 \%)$ & 27,3 & 30,7 & 42,0 & & $40(28,4 \%)$ & 141 \\
\hline 2001-2002 & $613(68,1 \%)$ & 46,8 & 47,1 & 6,0 & & $287(31,9 \%)$ & 900 \\
\hline $2002-2003$ & $117(36,0 \%)$ & 48,7 & 7,7 & 43,6 & & $208(64,0 \%)$ & 325 \\
\hline 2003-2004 & $438(99,5 \%)$ & 13,5 & 86,5 & 0,0 & & $2(0,5 \%)$ & 440 \\
\hline 2004-2005 & $701(84,0 \%)$ & 21,7 & 77,5 & 0,9 & & $134(16,0 \%)$ & 835 \\
\hline $2005-2006$ & $492(61,3 \%)$ & 50,2 & 11,6 & 38,2 & & $311(38,7 \%)$ & 803 \\
\hline 2006-2007 & $1.428(90,5 \%)$ & 35,2 & 62,5 & 2,2 & & $150(9,5 \%)$ & 1.578 \\
\hline $2007-2008$ & $789(46,5 \%)$ & 29,0 & 3,2 & 67,8 & & $906(53,5 \%)$ & 1.695 \\
\hline $2008-2009$ & $2.824(74,7 \%)$ & 38,8 & 59,6 & 1,6 & & $954(25,3 \%)$ & 3.778 \\
\hline $2009-2010$ & $6.441(98,7 \%)$ & 2,0 & 0,2 & 0,0 & 97,7 & $84(1,3 \%)$ & 6.525 \\
\hline
\end{tabular}

Desde el inicio de la pandemia en España se caracterizaron genéticamente 442 virus de la gripe, 355 (80\%) por el Centro Nacional de Gripe de la OMS del Centro Nacional de Microbiología del ISCIII (CNM, Majadahonda, Madrid) y 87 por el Laboratorio del Hospital N ${ }^{\mathrm{a}} \mathrm{Sr}^{\mathrm{a}}$ de Covadonga de Oviedo (Asturias). El 99\% del total de cepas caracterizadas en el territorio sujeto a vigilancia correspondieron a la cepa pandémica. El análisis filogenético de las cepas que circularon en España incluyó a las cepas estacionales AH3N2 y B dentro de los grupos en los que se encontraban las cepas vacunales de la temporada 2009-2010, mientras que todas las cepas de virus pandémico fueron similares a la cepa A/California/07/2009.

La mortalidad debida a gripe pandémica y gripe estacional, esta última en el periodo 2000-2008, se presenta en la figura 6. Un $64 \%$ de las defunciones por gripe pandémica se registraron en adultos jóvenes, entre 2564 años, con las mayores tasas de mortalidad en los grupos de 1-4 y de 45-64 años, grupo este último con la máxima tasa de mortalidad (9,35 defunciones por 1.000.000 habitantes). La mortalidad asociada a gripe estacional en el periodo 2000-2008 fue máxima en los mayores de 64 años, con más de $95 \%$ del total de defunciones en este periodo y una tasa promedio anual de 32 defunciones por 1.000.000 habitantes.

Se estimaron 744.795 casos confirmados de gripe por (H1N1)2009 desde mayo de 2009 hasta marzo de 2010 (tabla 6). Con 318 defunciones confirmadas por virus pandémico se calculó una cifra de letalidad global de 0,43 defunciones por 1.000 casos de gripe pandémica (IC95\%:0,38-0,48). La menor tasa de letalidad se observó en el grupo de 514 años $(0,05$ defunciones por 1.000 casos de gripe pandémica; IC95\%:0,03-0,09), grupo con la mayor incidencia estimada de gripe 
Figura 6

Porcentaje de defunciones y tasas de mortalidad debidas a gripe pandémica (A) y estacional (B). Periodo pandémico (mayo 2009-marzo 2010) y periodo 2000-2008. España

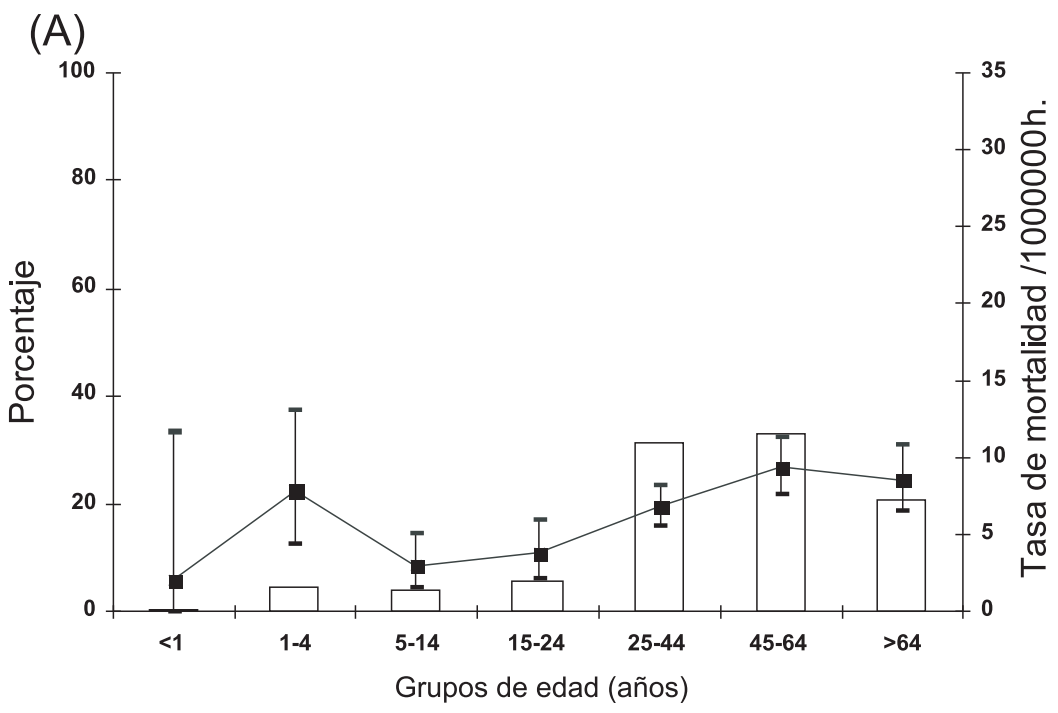

$\square$ Porcentaje de defunciones por gripe pandémica $\quad-$ Tasa de mortalidad poblacional

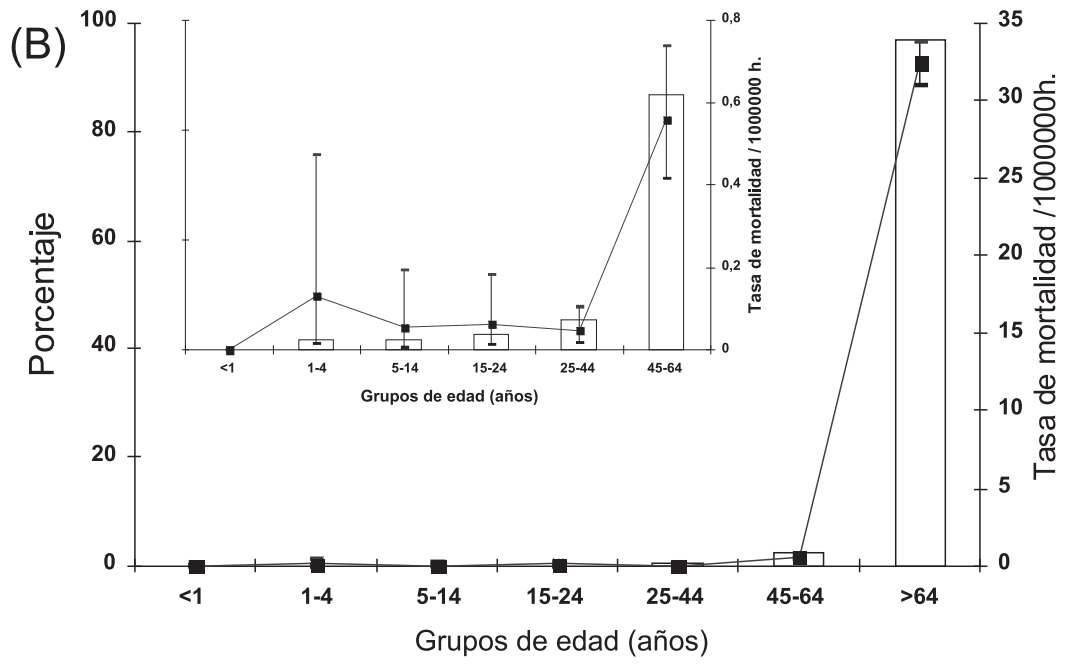

Tasa de mortalidad poblacional

confirmada por el virus pandémico. La mayor tasa de letalidad se registró en los mayores de
64 años con 4 defunciones por 1.000 casos de gripe pandémica (IC95\%:3,10-5,09). 
Tabla 6

Casos estimados confirmados de gripe pandémica por grupos de edad. Tasas de mortalidad y letalidad.

Mayo 2009- marzo 2010. España

\begin{tabular}{|c|c|c|c|c|c|c|}
\hline $\begin{array}{c}\text { Grupos } \\
\text { de edad } \\
\text { (años) }\end{array}$ & $\begin{array}{c}\mathbf{N}^{\mathbf{0}} \text { de casos } \\
\text { estimados } \\
\text { confirmados } \\
\text { de gripe } \\
\text { pandémica }\end{array}$ & $\begin{array}{c}\mathbf{N}^{\mathbf{0}} \text { de } \\
\text { defunciones }\end{array}$ & $\begin{array}{c}\text { Letalidad } \\
\text { (defunciones } \\
\text { por } \mathbf{1 . 0 0 0} \\
\text { casos } \\
\text { confirmados) }\end{array}$ & $\begin{array}{c}\text { Intervalo } \\
\text { Confianza } \\
\mathbf{9 5 \%}\end{array}$ & $\begin{array}{c}\text { Mortalidad } \\
\text { (defunciones } \\
\text { por 1.000.000 } \\
\text { habitantes) }\end{array}$ & $\begin{array}{c}\text { Intervalo } \\
\text { Confianza } \\
\mathbf{9 5 \%}\end{array}$ \\
\hline $0-4$ & 64.347 & 16 & 0,25 & $0,14-0,40$ & 6,75 & $3,86-11,00$ \\
\hline $5-14$ & 241.058 & 13 & 0,05 & $0,03-0,09$ & 3,00 & $1,60-5,13$ \\
\hline $15-64$ & 422.904 & 223 & 0,53 & $0,46-0,60$ & 7,27 & $6,35-8,29$ \\
\hline 764 & 16.486 & 66 & 4,00 & $3,10-5,09$ & 8,55 & $6,61-10,90$ \\
\hline Total & 744.795 & 318 & 0,43 & $0,38-0,48$ & 7,05 & $6,30-7,87$ \\
\hline
\end{tabular}

\section{DISCUSIÓN}

Desde la detección de los primeros casos del nuevo virus (H1N1)2009 en nuestro país, el patrón de detecciones de virus de la gripe cambió, observándose un aumento en el número de virus identificados, al mismo tiempo que un predominio absoluto del virus pandémico en las muestras analizadas en el conjunto del territorio sujeto a vigilancia. Experiencias previas de vigilancia virológica en las inter-temporadas gripales (de mayo a septiembre), a través del SVGE, siempre habían revelado una mínima circulación del virus de la gripe en nuestro territorio, fuera del periodo habitual de vigilancia integral de la enfermedad ${ }^{12}$, mientras que en ese mismo periodo del año 2009 los datos epidemiológicos y virológicos confirmaron una circulación sostenida del virus pandémico en España, que se prolongó durante todo el periodo estival y hasta el final de la onda pandémica en la temporada 2009-2010. Ahora bien, es muy posible que el estado de alerta en la población y en el personal sanitario, junto a las actividades complementarias del sistema de vigilancia, fueran responsables de una buena parte del incremento de actividad detectado durante el verano del 2009. En ese sentido, hay que tener en cuenta que, siguiendo las recomendaciones para el mantenimiento y refuerzo de la actividad del SVGE, el número de pacientes centinela a los que se tomó muestra para confirmación virológica en el verano de 2009 aumentó más de tres veces con respecto a las temporadas estacionales de gripe previas.

Junto al aumento en el número de muestras recogidas, también cambió la estrategia en la toma de muestras a lo largo del periodo de vigilancia, adoptándose una toma sistemática de muestras respiratorias para confirmación virológica. Ello probablemente facilitó la selección no sesgada de los pacientes y que la información virológica obtenida representara de forma más apropiada la distribución de casos de gripe en la comuni$\operatorname{dad}^{13}$.

Otras modificaciones introducidas en el inicio de la temporada 2009-2010 fueron, por una parte, la adopción de la definición de caso propuesta por la UE en aras de la homogeneidad en la vigilancia de gripe europea ${ }^{10}$ 
y, por otra, la recogida de información clínica y de factores de riesgo. Esto último permitió confirmar que el cuadro clínico producido por el virus pandémico era similar al de la gripe estacional y que un $13 \%$ de los casos de gripe que acudían a la consulta centinela de atención primaria presentaban factores de riesgo de complicaciones de gripe. La ausencia de información sobre prevalencia de factores de riesgo en casos diagnosticados en otras poblaciones generales impide hacer comparaciones válidas. Sólo se dispone de información sobre esa prevalencia en pacientes hospitalizados o fallecidos a causa del virus pandémico, donde se han llegado a dar cifras muy superiores (alrededor del $75 \%$ ) en diversos países de ambos hemisfe$\operatorname{rios}^{14}$.

A pesar de que la circulación de virus pandémico fue sostenida en España en el verano de 2009, la primera onda pandémica por virus (H1N1)2009 no se inició claramente hasta comienzos del otoño de 2009 , cuando a un aumento en la incidencia de la enfermedad clínica se unió un incremento en el porcentaje de muestras positivas o tasa de detección viral. Sin embargo, en términos de comparación con temporadas de gripe estacional previas, se puede decir que la intensidad de la circulación viral en España, según el valor global del anterior indicador (tasa de detección viral), se situó en el rango de valores registrados en el SVGE desde la temporada 2001$2002^{15}$. El carácter moderado de la pandemia se trasluce así mismo en la comparación del nivel de intensidad gripal y la duración de la onda pandémica, en relación a las temporadas de gripe previas. Aun así, su temprana presentación en el tiempo diferencia la onda pandémica de las ondas estacionales anteriores, ya que incluso antecedentes de ondas epidémicas precoces en el tiempo, en las temporadas 1996-1997 y 2003-2004, comenzaron tres y cinco semanas después que la onda pandémica por virus (H1N1)2009.

La pandemia por virus (H1N1)2009 también se ha caracterizado por el desplaza- miento prácticamente absoluto del resto de virus estacionales, coincidiendo con lo observado en la mayoría de países afectados por el virus en ambos hemisferios ${ }^{3,16} \mathrm{y}$ en contraposición al patrón mixto de circulación viral usual en las temporadas interpandémicas ${ }^{15}$. Por otra parte, todas las cepas de virus pandémico fueron similares a la cepa circulante a nivel mundial, A/California/07/2009, y hasta el momento no hay evidencias de una posible deriva antigénica o un cambio en la patogenicidad de la cepa pandémica circulante ${ }^{17}$.

En general, con algunas diferencias cuantitativas entre temporadas gripales, el mayor nivel de transmisión de la enfermedad ocurre siempre en menores de 15 años, tanto en España como en Europa ${ }^{15,18}$. Aun así, la onda pandémica por virus (H1N1)2009 produjo mayor carga de enfermedad que la gripe estacional en ese grupo de edad. Por el contrario, la incidencia en los mayores de 64 años se estima inferior en la pandemia, en relación a ondas estacionales de gripe previas. Se acepta que una posible explicación a este hecho reside en un cierto grado de protección contra la infección por virus (H1N1)2009 en personas de edad avanzada, debido a una inmunidad residual por exposición a cepas antigénicamente similares que circularon en la primera mitad del siglo pasado ${ }^{14,19}$.

Se ha estimado en cerca de un $10 \%$ el porcentaje de población española de 5-14 años que enfermó de gripe en España durante la primera onda pandémica por virus (H1N1)2009. Sin embargo, es difícil determinar la verdadera tasa de ataque de gripe pandémica, ya que tanto la gripe estacional como la pandémica muestran un amplio rango de presentaciones clínicas ${ }^{14}$, con una mayoría de infecciones leves y/o asintomáticas en las que la población no demanda atención médica ${ }^{13}$. De hecho, estudios serológicos sugieren tasas de ataque de gripe pandémica de hasta un $21 \%$ en niños menores de 5 años ${ }^{19}$ y hasta un $45 \%$ en población de 10 a 19 años $^{20}$. 
La gravedad de la pandemia por el virus de la gripe (H1N1)2009 ha sido descrita como de carácter leve en la mayor parte del mundo ${ }^{14,21,22}$ y favorable en comparación con las pandemias previas del siglo $\mathrm{XX}^{21}$. El patrón de letalidad por edad es similar al observado en las dos previas pandemias, pero con menores tasas de letalidad ${ }^{21,22}$. La tasa de letalidad global estimada en nuestra población $(0,4$ defunciones por 1.000 casos confirmados de gripe pandémica) está en el rango de las obtenidas por otros autores en Europa $^{21,23}$ y EEUU ${ }^{14}$ y la máxima letalidad se ha observado también en personas en edad avanzada, mucho menos susceptibles a la enfermedad.

Existen limitaciones para reflejar el impacto de la gripe pandémica con este indicador. Por una parte, la letalidad está seguramente sobreestimada porque el denominador no representa la tasa de ataque real de la enfermedad. Por otra, generalmente se asume que las cifras oficiales de defunciones por gripe suelen infraestimar la mortalidad atribuible a gripe tanto estacional como pandémica $^{24}$, entre otros factores porque muchas muertes relacionadas con la infección gripal son atribuidas oficialmente a patologías crónicas conocidas o complicaciones secundarias antes que a la infección gripal que precipitó realmente la muerte del paciente ${ }^{25}$.

Los esfuerzos por caracterizar la gravedad de la pandemia por virus (H1N1)2009 se dirigen en muchos casos, al igual que en este estudio, a comparar las defunciones confirmadas por virus pandémico con aquellas estimadas por gripe estacional. Sin embargo, los resultados de estas comparaciones deben interpretarse con mucha cautela. La mortalidad relacionada con gripe estacional se estima indirectamente mediante modelos que calculan el exceso de defunciones globales, o por algunos grupos de causas concretas, en periodos de circulación de virus gripales ${ }^{25-27}$, mientras que las defunciones atribuidas a gripe pandémica, notificadas a las autoridades sanitarias, son defunciones confirmadas por laboratorio de infección por virus (H1N1)2009, no son estimaciones. De todas formas, en relación con las temporadas anteriores de gripe estacional, sí se han observado variaciones en la mortalidad por edad que pueden anticipar su mayor relevancia. Así, mientras que más de un $90 \%$ de las defunciones por gripe se han dado en mayores de 64 años en las temporadas previas, en el periodo pandémico se invierte esa proporción y un $80 \%$ de las muertes se han producido en menores de 65 años. Además, la distribución por edad de las tasas de mortalidad por gripe pandémica refleja un patrón distinto del producido por la gripe estacional, observándose un desplazamiento de las máximas tasas de mortalidad en los mayores de 64 años en gripe estacional, a niños y adultos jóvenes durante la onda pandémica. Es precisamente este aspecto de mortalidad prematura el que intentan reflejar algunos autore ${ }^{28}$, aplicando el método normalmente utilizado de exceso de mortalidad en periodos de gripe estacional al periodo pandémico.

En conclusión, la onda pandémica por virus (H1N1)2009 tuvo una presentación precoz en España, en el otoño de 2009, y una intensidad moderada en comparación con ondas estacionales previas. Esta primera onda también se caracterizó por un carácter leve, teniendo en cuenta tasas de letalidad o mortalidad, si bien se observó un desplazamiento de las defunciones confirmadas por el virus pandémico a edades más jóvenes.

El SVGE se adaptó rápidamente a las recomendaciones de vigilancia y ha desempeñado un papel esencial en la vigilancia de la pandemia por virus (H1N1)2009 en España. Las mejoras introducidas en el SVGE, con motivo de la pandemia, pueden repercutir favorablemente en su funcionamiento y en la vigilancia de la actividad gripal en futuras ondas estacionales o pandémicas de gripe. Continuar caracterizando la intensidad y gravedad de estas ondas gripales, mediante los indicadores de morbilidad y mortalidad propuestos, es de suma impor- 
tancia, dado que anteriores pandemias han mostrado que no siempre el mayor impacto de salud se ha asociado a la primera onda pandémica $^{28}$.

\section{AGRADECIMIENTOS}

* Integrantes del SVGE: Médicos y pediatras de las redes centinela de vigilancia de gripe de: Andalucía, Aragón, Asturias, Baleares, Canarias, Cantabria, Castilla la Mancha, Castilla y León, Cataluña, Comunitat Valenciana, Extremadura, Madrid, Navarra, País Vasco, La Rioja, Ceuta y Melilla. Epidemiólogos miembros del SVGE pertenecientes a: Servicio de Vigilancia Epidemiológica y Evaluación, Consejería de Salud, Junta de Andalucía; Servicio de Vigilancia en Salud Pública, Dirección General de Salud Pública, Aragón; Dirección General de Salud Pública y Planificación, Conserjería de Salud y Servicios Sanitarios, Asturias; Servicio de Epidemiología, Dirección General de Salut Pública, Baleares; Servicio de Epidemiología y Prevención, Consejería de Sanidad de Canarias; Sección de Epidemiología, Consejería de Sanidad, Trabajo y Servicios Sociales de Cantabria; Servicio de Epidemiología, Consejería de Sanidad de Castilla la Mancha; Dirección General de Salud Pública e Investigación, Desarrollo e Innovación, Consejería de Sanidad de Castilla y León; Servicio de Vigilancia Epidemiológica, DGSP, Departament de Salut, Generalitat Catalunya; Àrea d'Epidemiologia, Conselleria de Sanitat, Comunitat Valenciana; Servicio de Epidemiología, Consejería de Bienestar Social, Junta de Extremadura; Direccion Xeral de Saúde Publica de Galicia; Dirección General de Atención Primaria de la Comunidad de Madrid; Servicio de Epidemiología. Consejería de Sanidad de la Región de Murcia; Sección de Vigilancia de Enfermedades Transmisibles, Instituto de Salud Pública de Navarra; Servicio de Vigilancia Epidemiológica, Consejería de Sanidad del País Vasco; Servicio de Epidemiología, Subdirección de Salud Pública de La
Rioja; Sección de Vigilancia Epidemiológica, Consejería de Sanidad y Bienestar Social de Ceuta; Dirección General de Sanidad y Consumo de Melilla; Centro Nacional de Epidemiología; Virólogos miembros del SVGE pertenecientes a: Centro Nacional de Referencia de Gripe (Centro Nacional de Gripe de la OMS del Centro Nacional de Microbiología (CNM), ISCIII, Majadahonda, Madrid); Hospital Virgen de las Nieves de Granada, Andalucía; Laboratorio del Hospital Miguel Servet de Zaragoza, Aragón; Laboratorio del Hospital $\mathrm{N}^{\mathrm{a}} \mathrm{Sr}^{\mathrm{a}}$ de Covadonga de Oviedo, Asturias; Laboratorio del Hospital Son Dureta de Palma de Mallorca, Baleares; Laboratorio del Hospital Dr. Negrín de Las Palmas de Gran Canaria, Canarias; Laboratorio del Hospital Universitario Marqués de Valdecilla de Santander; Centro Nacional de Gripe de la Facultad de Medicina de Valladolid; Instituto Valenciano de Microbiología, Valencia, Comunitat Valenciana; Centro Nacional de Gripe del Hospital Clínico de Barcelona; Hospital San Pedro de Alcántara de Cáceres, Extremadura; Servicio de Microbiología del Hospital Universitario Ramón y Cajal; Madrid, Comunidad de Madrid; Laboratorio de la Clínica Universitaria de Navarra, Pamplona, Navarra; Laboratorio de Microbiología. Hospital Donostia, País Vasco; Hospital San Pedro de la Rioja de Logroño, La Rioja; Laboratorio de Microbiología del Hospital de INGESA de Ceuta; Laboratorios de Microbioloxía $\mathrm{CH}$ de Vigo y de Ourense (Galicia) y Hospital Virgen de la Arrixaca de Murcia.

Los autores agradecen la valiosa contribución del Centro de Coordinación de Alertas y Emergencias del Ministerio de Sanidad y Política Social, y la del Subcomité de Vigilancia del Plan Nacional de Preparación y Respuesta a una pandemia de gripe, ambos involucrados en la adaptación de las estrategias de vigilancia de la pandemia de acuerdo con la evolución de la misma en España. 


\section{BIBLIOGRAFÍA}

1. CDC. Swine Influenza A (H1N1) Infection in Two Children-Southern California, March-April 2009. MMWR. 2009;58:400-402.

2. World Health Organisation. Current WHO phase of pandemic alert. Disponible en: http://www. who.int/csr/disease/avian_influenza/phase/en/

3. OMS. Informes de situación. Disponible en: http://www.who.int/csr/disease/swineflu/updates/e n/index.html.

4. Surveillance Group for New Influenza (H1N1) Virus Investigation and Control in Spain. New influenza (H1N1) virus infections in Spain, AprilMay 2009. Euro Surveill. 2009;14(19):pii=19209. Disponible en: http://www.eurosurveillance.org/ ViewArticle.aspx?ArticleId=19209.

5. Ministerio de Sanidad y Política Social. Plan Nacional de Preparación y Respuesta frente a una pandemia de gripe. Vigilancia epidemiológica de casos humanos de infección por virus pandémico (H1N1)2009. 9 de septiembre de 2009. Madrid: Ministerio de Sanidad y Política Social; 2009. Disponible en: http://www.msc.es/profesionales/ saludPublica/gripeA/docs/VigilanciaVirusPandemico2009.pdf.

6. European Centre for Disease Prevention and Control. Surveillance and studies in a pandemic: Fourth meeting of the SSiaP working group. ECDC Meeting Report. Stockholm, July 2009. Disponible en: http:/www.ecdc.europa.eu/en/publications/Pages/ Meeting_Reports.aspx.

7. Ministerio de Sanidad y Política Social. Cambio en el sistema de información sobre los casos de gripe A/ H1N1 en situación de pandemia en fase 6. Disponible en: http:/www.msc.es/servCiudadanos/ alertas/informesGripeA/090728.htm.

8. European Centre for Disease Prevention and Control. European Influenza Surveillance Network (EISN). Disponible en: http://ecdc.europa.eu/ en/activities/surveillance/EISN/Pages/home.aspx.

9. International Classification of Health Problems in Primary Care (ICHPPC-2-Defined). Barcelona: Masson SA, 1988. (Spanish Edition).

10. European Commission. Commission Decision 2009/363/EC of 30 April 2009 amending Decision 2002/253/EC laying down case definitions for reporting communicable diseases to the Community network under Decision No 2119/98/EC of the
European Parliament and of the Council, OJ L 110, 1.5.208, p. 58. Disponible en: http://eur-lex.europa.eu/LexUriServ/LexUriServ.do?uri=OJ:L:2009: 110:0058:0059:EN:PDF.

11. Tomás Vega, José E Lozano, John W Paget, Pauline Slottje, Raul Ortíz, Marisol Gutierrez, José María Eiros and the EISS Baseline Working Group. Validation of the Moving Epidemic Method for detecting influenza epidemics in Europe. Poster. Options for the Control of Influenza VI, 17-23 June 2007, Toronto, Ontario, Canadá. Disponible en: http://www.isirv.org/media/pdf/OptionsVI_proceedings.pdf.

12. Jiménez-Jorge S., Larrauri A., De Mateo S, et al. Vigilancia de la gripe en España. Resumen de la temporada 2007-2008. Bol Epidemiolo Sem. 2008. 16(11):121-128. Disponible en. http://www.isciii. es/jsps/centros/epidemiologia/listaBoletinesHistorico.jsp?year $=2008$.

13. WHO European guidance for influenza surveillance in humans. 2009. Disponible en: http:// www.euro.who.int/influenza/news/20090825_1.

14. WHO. Writing Committee of the WHO Consultation on Clinical Aspects of Pandemic (H1N1) 2009 Influenza. Clinical Aspects of Pandemic 2009 Influenza A (H1N1) Virus Infection. N Engl J Med. 2010;362:1708-19.

15. Informes de Vigilancia de Gripe en España. Sistema de Vigilancia de la Gripe en España. Red Nacional de Vigilancia Epidemiológica. Centro Nacional de Epidemiología. Disponible en: http://vgripe.isciii.es/gripe/.

16. ECDC. Informes semanales de vigilancia de gripe. Informes de situación. European Influenza Surveillance Network (EISN). Disponible en: http:// ecdc.europa.eu/en/activities/surveillance/EISN/Pa ges/EISN_Bulletin.aspx.

17. ECDC Risk Assessment. Likely scenarios for influenza in 2010 and the 2010/2011 influenza season in Europe and the consequent work priorities. Disponible en: http://ecdc.europa.eu/en/healthtopics/H1N1/Pages/risk_assessment.aspx.

18. Paget J, Marquet R, Meijer A, van der Velden K. Influenza activity in Europe during eight seasons (1999-2007): an evaluation of the indicators used to measure activity and an assessment of the timing, length and course of peak activity (spread) across Europe. BMC Infect Dis. 2007;7(1):141.

19. Miller E, Hoschler K, Hardelid P, Stanford E, Andrews N, Zambon M. Incidence of 2009 pandemic influenza A H1N1infection in England: a 
cross-sectional serological study. Lancet. 2010;375:1100-8.

20. Ross T, Zimmer S, Burke D, Crevar C, Carter D, Stark J, et al. Seroprevalence following the second wave of pandemic 2009 H1N1 influenza. PLoS Curr Influenza. 2010; February 24:RRN1148.

21. Donaldson LJ, Rutter PD, Ellis BM, Greaves FE, Mytton OT, Pebody RG et al. Mortality from pandemic A/H1N1 2009 influenza in England: public health surveillance study. BMJ. 2009;339: b5213.

22. Kilbourne ED. Influenza pandemics of the 20th century. Emerg Infect Dis. 2006; 12:9-14.

23. Pebody RG, McLean E, Zhao H, Cleary P, Bracebridge $\mathrm{S}$, Foster $\mathrm{K}$ et al. Pandemic Influenza A (H1N1) 2009 and mortality in the United Kingdom: risk factors for death, April 2009 to March 2010. Euro Surveill. 2010;15(20):pii=19571. Disponible en: http://www.eurosurveillance.org/ViewArticle.aspx?ArticleId=19571.

24. WHO Comparing deaths from pandemic and seasonal influenza. Pandemic (H1N1) 2009 briefing note 20 December 22nd 2009. Disponible en: http://www.who.int/csr/disease/swineflu/notes/bri efing_20091222/en/index.html.

25. Morens DM. Influenza-related mortality: considerations for practice and public health. JAMA. 2003;289:227-229.

26. Simonsen L, Clarke MJ, Williamson GD et al. The impact of influenza epidemics on mortality: introducing a severity index. Am J Public Health. 1997;87:1944-1950.

27. López-Cuadrado T, Larrauri A, Jimenez S, de Mateo S. «Influenza-Associated to Hospitalizations and Deaths in Spain». International Meeting on Emerging Diseases and Surveillance. IMED, February 13-16 2009, Viena, Austria. Disponible en: http://ww2.isid.org/abstracts/Conference_AbstDetail.lasso abstractid $=380$.

28. Viboud C, Miller M, Olson D, Osterholm M, Simonsen L. Preliminary estimates of mortality and years of life lost associated with the $2009 \mathrm{~A} / \mathrm{H} 1 \mathrm{~N} 1$ pandemic in the US and comparison with past Influenza seasons PLoS Curr Influenza. 2010 March 20: RRN1153. Disponible en: http://www.ncbi.nlm.nih. gov/pmc/articles/PMC2843747. 